\title{
Learning Algorithms \\ Theory and Applications
}




\section{S. Lakshmivarahan}

\section{Learning Algorithms \\ Theory and Applications}

Springer-Verlag

New York Heidelberg Berlin 
Prof. S. Lakshmivarahan

University of Oklahoma

School of Electrical Engineering

and Computer Science

Norman, Oklahoma 73019

\section{Library of Congress Cataloging in Publication Data}

Lakshmivarahan, S.

Learning algorithms theory and applications.

Bibliography: $\mathrm{p}$.

Includes index.

1. Artificial intelligence. 2. Algorithms.

3. Learning. I. Title.

Q335.L34 001.53'5 81-16683

AACR2

(C) 1981 by Springer-Verlag New York Inc.

Softcover reprint of the hardcover 1st edition 1981

All rights reserved. No part of this book may be translated or reproduced in any form without written permission from Springer-Verlag, 175 Fifth Avenue, New York, New York 10010, U.S.A.

The use of general descriptive names, trade names, trademarks, etc. in this publication, even if the former are not especially identified, is not to be taken as a sign that such names, as understood by the Trade Marks and Merchandise Marks Act, may accordingly be used freely by anyone. 
DEDICATED TO

MY

FA'THER and MOTHER

Who taught me many useful algorithms. 


\section{PREFACE}

Learning constitutes one of the most important phase of the whole psychological processes and it is essential in many ways for the occurrence of necessary changes in the behavior of adjusting organisms. In a broad sense influence of prior behavior and its consequence upon subsequent behavior is usually accepted as a definition of learning. Till recently learning was regarded as the prerogative of living beings. But in the past few decades there have been attempts to construct learning machines or systems with considerable success.

This book deals with a powerful class of learning algorithms that have been developed over the past two decades in the context of learning systems modelled by finite state probabilistic automaton. These algorithms are very simple iterative schemes. Mathematically these algorithms define two distinct classes of Markov processes with unit simplex (of suitable dimension) as its state space. The basic problem of learning is viewed as one of finding conditions on the algorithm such that the associated Markov process has prespecified asymptotic behavior. As a prerequisite a first course in analysis and stochastic processes would be an adequate preparation to pursue the development in various chapters. Automaton models and algorithms for learning, which is the central theme of the present book, have been widely accepted as one of the fundamental approaches to machine intelligence. In spite of this wide spread acceptability most of the published material on this topic to date are confined to articles in research journals or isolated chapters in anthologies and as such there is no one single text book or monograph on this topic. This book is intended to fill this gap. 
The book consists of two parts: Part I developes the theory of design of learning algorithms. In particular it deals with the convergence behavior of various classes of learning algorithms. Part II describes the application of these algorithms to decentralized decision making problems with incomplete information. More specifically, we deal with the applications to two person zero sum sequential games with incomplete information, two person team problem with incomplete information and Markov decision problem with incomplete information.

Our aim is to provide a unified framework and a comprehensive treatment of most of the results pertaining to both the theory and applications known to date. Interestingly enough, much of the results presented in Part II came into existence only during the past three to four years.

Basically, the book arose out of the notes written by the author for a series of lectures delivered at the Institute of Applied Mathematics, University of Bonn,W. Germany during January 1980 under the auspecies of their Sonderforschungsbereiches. A major part of an earlier version was also used for the graduate course CS 5070, Seminar in Problem Solving at the School of Electrical Engineering and Computer Science, University of Oklahoma during Spring Semester 1980 .

The author wishes to record his sincere appreciation and thanks to Professors R. Leis, W. Voge1, V. Herkenrath and D. Kalin of the University of Bonn for arranging this visit and their hospitality. Special thanks are due to Professors Herkenrath and Kalin with whom the author has spent countless hours discussing various aspects of both the theory and applications of learning algorithms. Dr. Herkenrath read through the entire manuscript and has suggested various improvements. It was Professor Radu Theodorescu of Laval University who introduced the author to the University of Bonn. Our thanks are due to him and his collaborator 
Professor M. Iosifescu for their constant encouragement. Professor M.A.L. Thathachar initiated the author into the field of learning algorithms when he was a graduate student at the Department of Electrical Engineering, Indian Institute of Science, Bangalore, India. Ever since that time, he has been a great source of inspiration and continued guidance. His influence will be felt throughout the book and the author is deeply indebted to him. Much of the work in Part II (Chapters 5 through 7) was carried out when the author was at Yale University during 1976 - 1978 under the direction of Professor K.S. Narendra. It was Professor Narendra who introduced the author into the exciting area of learning approach to decentralized decision making with incomplete information. To him we are very grateful for his continued advice and support. In addition, quite a variety of people have helped the author in many different ways. Professor H.J. Kushner helped to clarify many intricacies of different classes of learning algorithms. In fact, his well known counter example marked a definite turning point (for the better) in our research work. Professors K.S. Fu, M.D. Srinath and $\mathrm{H}$. Aso have read through the various portions of the manuscript and have suggested various modifications. Professors M.E. Council and S.K. Kahng (past and present directors) of the School of Electrical Engineering and Computer Science, University of Oklahoma have extended full support for the completion of this work. The Mathematics editorial staff of Springer Verlag, Inc. New York handled this project with great care and patience. Our sincere appreciation and thanks are due to all these above individuals. Thanks are also due to Betty Sudduth, Vici Chance and Ronda Sharp for typing various portions of the manuscript. Finally, to all members of my family, especially my wife Shantha and our children, Subha and Bharathram for their understanding and help (too numerous to 
list) words are not enough to adequately thank them.

Norman, Oklahoma

July 1981

S. Lakshmivarahan 


\section{TABLE OF CONTENTS}

\section{PART 1, THEORY}

\section{INTRODUCTION}

1.1. Various Approaches to Learning 1

1.2. A Learning Algorithm 2

1.3. Performance Measures and Statement of Problem 4

1.4. Classification of Learning Algorithms 6

1.5. Organization of the Book 9

1.6. Comments and Historical Remarks 13

$\begin{array}{ll}\text { 1.7. Exercises } & 18\end{array}$

2. ERGODIC LEARNING ALGORITHMS

2.1. Introduction 19

2.2. $\mathrm{N}_{\mathrm{R}-\mathrm{P}}^{\mathrm{E}}$ - Algorithm 20

2.3. Analysis 23

2.4. An Alternate Characterization of $z(k) \quad 44$

2.5. Simulations $(M=2) \quad 45$

2.6. Analysis and Simulations: General Case $M \geq 2 \quad 48$

2.7. Comments and Historical Remarks 59

2.8. Appendix 60

2.9. Exercises 63

3. ABSOLUTELY EXPEDIENT LEARNING ALGORITHMS

3.1. Introduction 66

3.2. $\mathrm{N}_{\mathrm{R}-\mathrm{P}}^{\mathrm{A}}$ Algorithm $\quad 67$

3.3. Conditions for Absolute Expediency 69 
3.4. Analysis of Absolutely Expedient Algorithms 73

3.5. An Algorithm to Compute Bounds 80

3.6. Absolute Expediency and $\varepsilon$-Optimality 89

$\begin{array}{lr}\text { 3.7. Simulations } & 92\end{array}$

3.8. Comments and Historical Remarks 96

$\begin{array}{lr}\text { 3.9. Appendix } & 97\end{array}$

$\begin{array}{lr}\text { 3.10. Exercises } & 104\end{array}$

\section{TIME VARYING LEARNING ALGORITHMS}

$\begin{array}{lr}\text { 4.1. Introduction } & 109\end{array}$

4.2. A Time Varying Learning Algorithm 111

4.3. Kushner's Method of Asymptotic Analysis 115

A. Convergence with Probability One $\quad 118$

B. Weak Convergence $\quad 122$

4.4. Comments and Historical Remarks 125

4.5. Appendix 127

$\begin{array}{lr}\text { 4.6. Exercises } & 135\end{array}$

PART II. APPLICATIONS

5. TWO-PERSON ZERO-SUM SEOUENTIAL, STOCHASTIC GAMES WITH IMPERFECT AND INCOMPLETE INFORMATION-GAME MATRIX WITH SADDLE-POINT IN PURE STRATEGIES

$\begin{array}{lr}\text { 5.1. Introduction } & 137\end{array}$

5.2. The $L_{R-I}^{A}$ - Algorithm and Statement of Results 140

5.3. Analysis of Games $r$

5.4. Special Case - Dominance 153

$\begin{array}{lr}\text { 5.5. Simulations } & 159\end{array}$

5.6. Comments and Historical Remarks 161 
5.7. Appendix 164

5.8. Exercises

6. TWO-PERSON ZERO-SUM SEQUENTIAL, STOCHASTIC GAMES WITH IMPERFECT AND INCOMPLETE INFORMATION - GENERAL CASE

$\begin{array}{lr}\text { 6.1. Introduction } & 168\end{array}$

6.2. $\mathrm{L}_{\mathrm{R}-\mathrm{P}}^{\mathrm{E}}$ Algorithm $r$

6.3. Analysis of Game 171

$\begin{array}{lr}\text { 6.4. Extensions } & 187\end{array}$

$\begin{array}{lr}\text { 6.5. Simulations } & 188\end{array}$

$\begin{array}{lr}\text { 6.6. Comments and Historical Remarks } & 188\end{array}$

6.7. Appendix 192

$\begin{array}{lr}\text { 6.8. Exercises } & 195\end{array}$

7. TWO-PERSON DECENTRALISED TEAM PROBLEM WITH INCOMPLETE INFORMATION

$\begin{array}{lr}7.1 . & 197\end{array}$

7.2. Analysis of Decentralised Team Problem $L_{R-P}^{E}$ Algorithm 200

7.3. Analysis of Decentralised Team Problem $\mathrm{L}_{\mathrm{R}-\mathrm{I}}^{\mathrm{A}}$ Algorithm 222

$\begin{array}{lr}\text { 7.4. Simulations } & 225\end{array}$

7.5. Comments and Historical Remarks 226

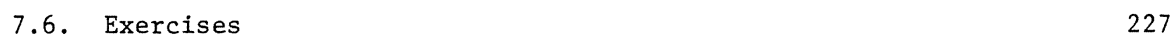

8. CONTROL OF A MARKOV CHAIN WITH UNKNOWN DYNAMICS AND COST-STRUCTURE

$\begin{array}{lr}\text { 8.1. Introduction } & 228\end{array}$

8.2. Definitions and Statement of Problem 229

8.3. Learning Algorithm 236

8.4. Analysis 238

$\begin{array}{llr}8.5 & \text { Simulations } & 244\end{array}$ 
8.6. Extension to Delayed State Observations 249

8.7. Comments and Historical Remarks 253

8.8. Exercises 256

$\begin{array}{lr}\text { Epilogue } & 257\end{array}$

$\begin{array}{lr}\text { References } & 259\end{array}$

$\begin{array}{lr}\text { Index } & 274\end{array}$ 